\title{
Radiographic and Clinical Results of C1 Laminoplasty for the Treatment of Compressive Myelopathy
}

\author{
Kiyoshi Tarukado ${ }^{1}$, Ko Ikuta ${ }^{2}$, Keiichiro Iida ${ }^{1}$, Osamu Tono ${ }^{1}$, Toshio Doi ${ }^{1}$, Katsumi Harimaya ${ }^{1}$ \\ ${ }^{1}$ Department of Orthopaedic Surgery, Kyushu University Beppu Hospital, Beppu, Japan \\ ${ }^{2}$ Department of Orthopaedic Surgery, Karatsu Red Cross Hospital, Karatsu, Japan
}

Study Design: Case series.

Purpose: To evaluate the radiographic and clinical results of $\mathrm{C} 1$ laminoplasty without fusion.

Overview of Literature: $\mathrm{C} 1$ laminectomy has been the standard procedure for decompression at the $\mathrm{C} 1$ level. However, there have been some reports of trouble cases after $\mathrm{C} 1$ laminectomy. $\mathrm{C} 1$ laminoplasty might be superior to $\mathrm{C} 1$ laminectomy with regard to maintaining the original $\mathrm{C} 1$ anatomical shape, preventing compression from the posterior soft tissue, and ensuring an adequate bonegrafting site around the $\mathrm{C} 1$ posterior part if additional salvage fusion surgery is necessary afterward.

Methods: Seven patients with spinal cord compression without obvious segmental instability at the C1/2 level treated by $\mathrm{C} 1$ laminoplasty were included. The indication of $\mathrm{C} 1$ laminoplasty was same as that of $\mathrm{C} 1$ laminectomy. $\mathrm{C} 1$ laminoplasty was performed in the same way as subaxial double-door laminoplasty. The imaging findings were evaluated using X-ray, computed tomography, and magnetic resonance imaging. The clinical results were evaluated using the Japanese Orthopaedic Association (JOA) Cervical Myelopathy Evaluation Questionnaire (JOACMEO) and JOA score. Peri- and postoperative complications were also investigated.

Results: No patient showed increased C1/2 segmental instability after the surgery. The mean pre- and postoperative JOA scores were 8.6 and 11.7 , respectively. The mean recovery rate was $40.2 \%$. The effective rate in the JOACMEO was $50 \%$ for the cervical spine function, 33\% for the upper extremity function, $50 \%$ for the lower extremity function, $17 \%$ for the bladder function, and $17 \%$ for the quality of life. No major complication that seemed to be unique to $\mathrm{C} 1$ laminoplasty was observed over a period of about 4 years follow-up.

Conclusions: $\mathrm{C} 1$ laminoplasty for patients without obvious segmental instability might be a viable alternative procedure to $\mathrm{C} 1$ laminectomy.

Keywords: Cervical atlas; Spinal cord compression; Compressive myelopathy; Laminoplasty

\section{Introduction}

C1 laminectomy has been the standard procedure for decompression at the $\mathrm{C} 1$ level $[1,2]$. Discussion has been had regarding whether fusion surgery or decompression surgery is a better treatment for compressive myelopathy with pseudotumor at the upper cervical level. However, the methodology of decompression surgery has hardly

Received Jun 11, 2019; Revised Aug 5, 2019; Accepted Sep 19, 2019

Corresponding author: Kiyoshi Tarukado

Department of Orthopaedic Surgery, Kyushu University Beppu Hospital, 4546 Tsurumihara, Tsurumi, Beppu, Oita 874-0838, Japan

Tel: +81-977-27-1755, Fax: +81-977-27-1755, E-mail: kt99059@hotmail.com 
been discussed. Recently, there have been some reports of spontaneous anterior arch fracture after $\mathrm{C} 1$ laminectomy [3-8]. Anterior arch fragility following C1 laminectomy has also been recognized using a finite element analysis [6]. In addition, a case of dynamic paraspinal muscle impingement causing acute hemiplegia after $\mathrm{C} 1$ laminectomy was recently reported [9]. Historically, cervical laminoplasty has been developed to avoid some issues after cervical laminectomy, such as laminectomy scar membrane at the middle and lower cervical levels. Considering the historical background and based on the findings of the previous reports, it may therefore be better to change $\mathrm{C} 1$ laminectomy to another method, such as $\mathrm{C} 1$ laminoplasty.

We have performed $\mathrm{C} 1$ laminoplasty without fusion in some patients with compressive myelopathy without obvious instability at the $\mathrm{C} 1$ level. $\mathrm{C} 1$ laminoplasty might be superior to $\mathrm{C} 1$ laminectomy with regard to maintaining the original $\mathrm{C} 1$ anatomical shape, preventing compression from the posterior by muscle impingement, and ensuring an adequate bone-grafting site around the $\mathrm{C} 1$ posterior part if additional salvage fusion surgery is necessary afterward.

The purpose of this study is to evaluate the radiographic and clinical results of $\mathrm{C} 1$ laminoplasty without fusion for patients with compressive myelopathy without obvious instability at the $\mathrm{C} 1$ level.

\section{Materials and Methods}

All the procedures performed in studies involving human participants were in accordance with the ethical standards of the institutional and/or national research committee and with the 1964 Helsinki declaration and its later amendments or comparable ethical standards. Informed consent was obtained from all the individual participants included in this study. This study was approved by the ethics committee of Kyushu University Hospital (IRB approval no., 28-324).

A total of eight patients (seven males, one female) who underwent C1 laminoplasty between January 2010 and March 2018 were retrospectively reviewed. The indications of $\mathrm{C} 1$ laminoplasty, same as those of $\mathrm{C} 1$ laminectomy, are summarized subsequently. Compressive myelopathy at the $\mathrm{C} 1$ level was confirmed using magnetic resonance imaging (MRI). Obvious instability, which was defined as movement exceeding $3 \mathrm{~mm}$ at the atlas-dens interval (ADI), was denied using dynamic lateral X-ray.
In this series, $\mathrm{C} 1$ laminoplasty was performed on patients who satisfied the abovementioned points. Contraindications of $\mathrm{C} 1$ laminoplasty are patients with great instability, bone anomaly, and anomaly of the vertebral artery.

$\mathrm{C} 1$ laminoplasty was performed as follows: First, we expose the $\mathrm{C} 1$ posterior arch, perform fenestration at $\mathrm{O}-\mathrm{C} 1$ and $\mathrm{C} 1-2$, pass through a $\mathrm{T}$-saw under the $\mathrm{C} 1$ posterior arch in case using T-saw, cut the center of the posterior arch using a T-saw (six cases) or high-speed drill (two cases), make gutters at the bilateral sides using high-speed drill with $3 \mathrm{~mm}$ diamond bar, open the posterior arch, and finally piece together the split arches using a hydroxyapatite (HA) spacer with suture (Fig. 1). The $\mathrm{C} 1$ posterior arch has much cortical bone than the subaxial laminae. It is difficult to make gutters; so, care must be taken not to cause incidental fracture. In case with multiple stenosis at subaxial laminae, double-door laminoplasty involving placement of HA spacer was performed.

The mean age, preoperative diagnosis, operated level, estimated blood loss (EBL), operation time (OT), segmental instability at the $\mathrm{C} 1 / 2$ before and after surgery, bone union of gutters, anteroposterior (AP) diameter of spinal canal at the $\mathrm{C} 1$ level after surgery, clinical results, and follow-up (FU) period were reviewed. Patients with less than 1 year of FU were excluded from this study. The
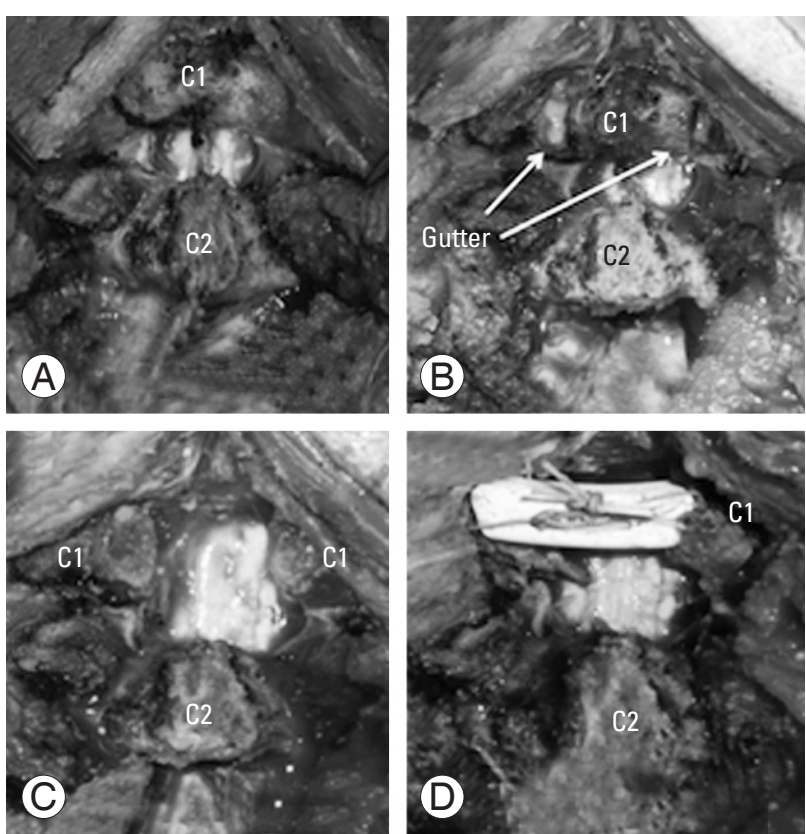

Fig. 1. The surgical procedures of $\mathrm{C} 1$ laminoplasty. (A) Exposure and cutting the laminar. (B) Making the gutter. (C) Splitting the laminar. (D) Piece together using a hydroxyapatite spacer. 
thickness of the pseudotumor was measured before and after surgery, and the difference in the size was calculated. Peri- and postoperative complications were also investigated. Radiographic evaluation was performed at 1 year or later after the surgery. Clinical evaluation was performed at preoperation, 1 year after the surgery, and final FU. If revision surgery was needed, that time was considered as the final FU.

Instability of the $\mathrm{C} 1 / 2$ was evaluated using dynamic lateral X-ray on the picture archiving and communication systems before and after surgery. Segmental instability was defined as movement exceeding $3 \mathrm{~mm}$ at the ADI [8]. Bone union of the gutters and that between the HA spacer and posterior elements were assessed using computed

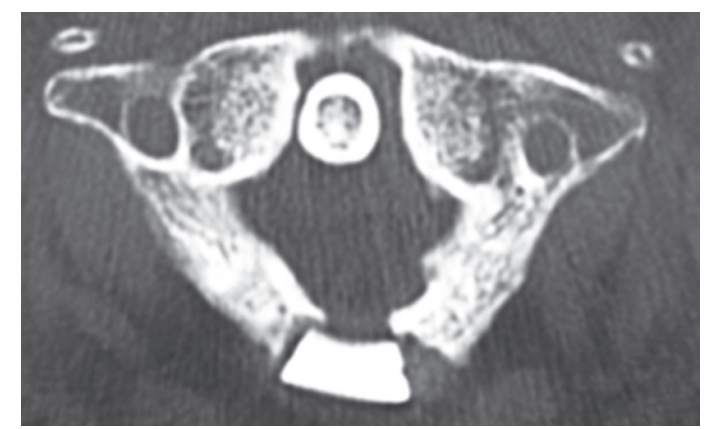

Fig. 2. Osteogenesis was seen in the gap of the gutters at 1 year and 6 months after surgery.

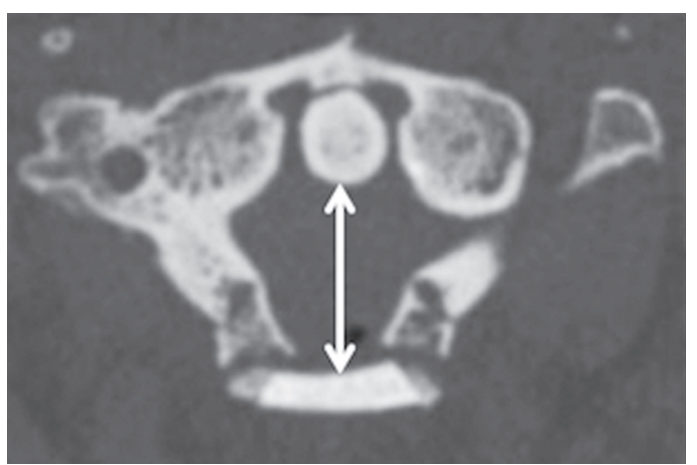

Fig. 3. The anteroposterior diameter of the spinal canal at the $\mathrm{C} 1$ level was measured between the posterior surface of the dens and the anterior surface of the hydroxyapatite spacer after the surgery as indicated by the white arrow. tomography (CT) during FU. Bone union was defined as the bridging of the gap of the gutter with time (Fig. 2). The AP diameter of the spinal canal at the $\mathrm{C} 1$ level was measured between the posterior surface of the dens and the anterior surface of the HA spacer after surgery using CT (Fig. 3). Clinical results were evaluated using the Japanese Orthopaedic Association (JOA) score [10] and the Hirabayashi's recovery rate [11]. In addition, the JOA Cervical Myelopathy Evaluation Questionnaire (JOACMEQ) was used to evaluate the clinical results as patientbased outcomes in patients with complete data [12]. The JOACMEQ has several domains, including cervical spine function, upper extremity function, lower extremity function, bladder function, and quality of life. The effectiveness of the treatment based on the JOACMEQ was judged following the methods determined by the JOA (Table 1).

\section{Results}

A total of seven patients (six males, one female) who underwent $\mathrm{C} 1$ laminoplasty were ultimately included. One patient with less than one year FU was excluded. The mean age of the patients at the time of surgery was 72 years old. The mean FU period after surgery was 50 months (range, 22-78 months). Cervical ossification of the posterior longitudinal ligament was demonstrated in one patient, and cervical spondylotic myelopathy was demonstrated in six patients. Atlantoaxial anterior subluxation and retroodontoid pseudotumor were revealed in five patients. There were some overlaps in the diagnoses. The treated level was as follows: C1-6 in two cases, C1 and C3-6 in three cases, $\mathrm{C} 1$ and C3-5 in one case, and C1 in one case. The mean EBL was $269 \mathrm{~g}$ (range, 40-734 g). The mean OT was 211 minutes (range, 163-270 minutes). No patient showed an obvious increase in $\mathrm{C} 1 / 2$ segmental instability after the surgery.

Adequate decompression was observed in all patients using CT, and the mean C1-level spinal column AP diameter was $23 \mathrm{~mm}$. Sufficient decompression was also

Table 1. Therapeutic effect of treatment

\section{Contents}

Treatment effectiveness for individual patients

Effective rate for a group
(1) The post-treatment score increases by $\geq 20$ points compared to the pretreatment score.

(2) The pretreatment score is $<90$, and the post-treatment score is $\geq 90$ points.

If either (1) or (2) is satisfied, the treatment is judged "effective".

(No. of patients judged "effective")/\{(total no. of patients in the group)-(no. of patients whose pre- and posttreatment scores were both $\geq 90)\}$ 


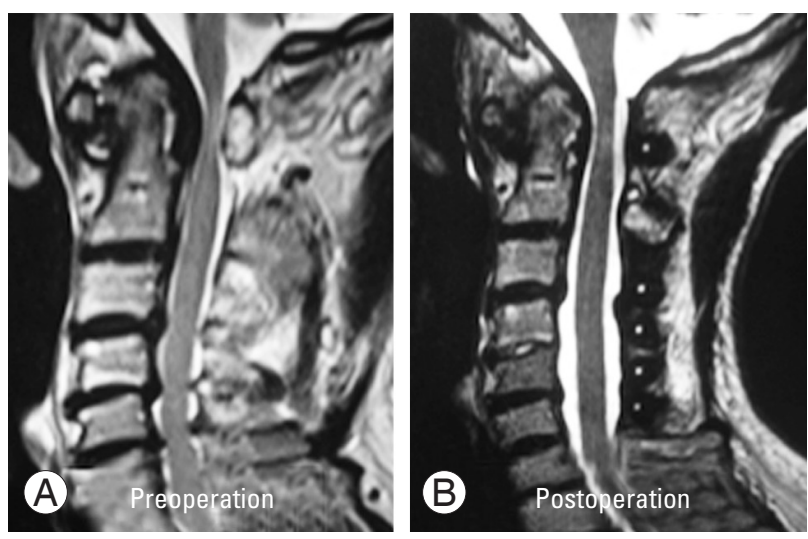

Fig. 4. (A, B) MRI compared before and after the surgery. Sufficient decompression was confirmed by MRI after the surgery. MRI, magnetic resonance imaging.

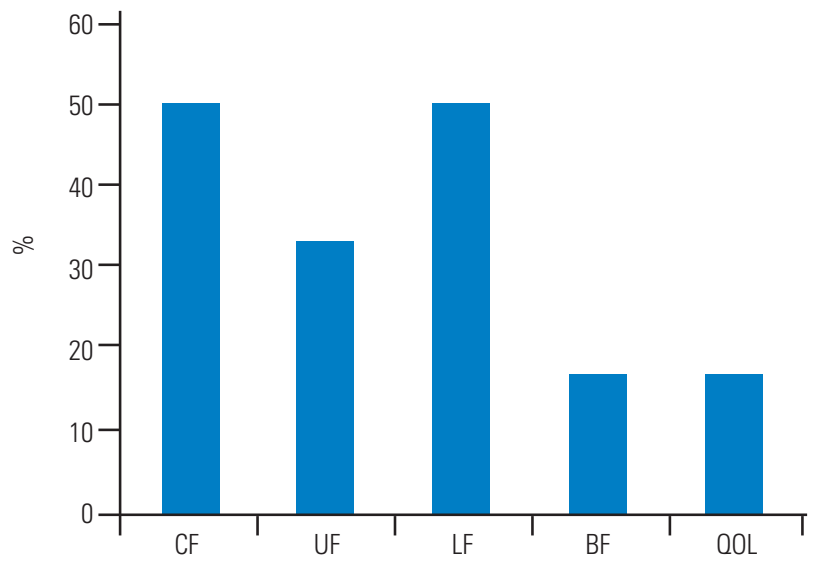

Fig. 5. The therapeutic effective rate calculated according to Table 1. The therapeutic effective rate of the BF and QOL tended to be lower than those of the $C F$, UF, or LF. CF, cervical spine function; UF, upper extremity function; LF, lower extremity function; $\mathrm{BF}$, bladder function; $\mathrm{QOL}$, quality of life.

confirmed in MRI (Fig. 4). Bone union of the gutters was accomplished in five of seven cases during FU (Table 2). For the remaining two patients, the gutter on one side was fused. The mean thickness of the pseudotumor before and after surgery was $8.7 \mathrm{~mm}$ and $9.3 \mathrm{~mm}$, respectively.

The mean JOA scores before surgery, one year after surgery, and final FU were 8.6, 12.2, and 11.7, respectively. The mean recovery rates at 1 year after surgery and final FU were $42.9 \%$ and $40.2 \%$, respectively (Table 3 ). According to the JOA evaluation system for the effectiveness of treatment as determined by the JOACMEQ, the effective rate was $50 \%$ for the cervical spine function, $33 \%$ for the upper extremity function, $50 \%$ for the lower extremity function, $17 \%$ for the bladder function, and $17 \%$ for the quality of life (Fig. 5). The original anatomical shape as

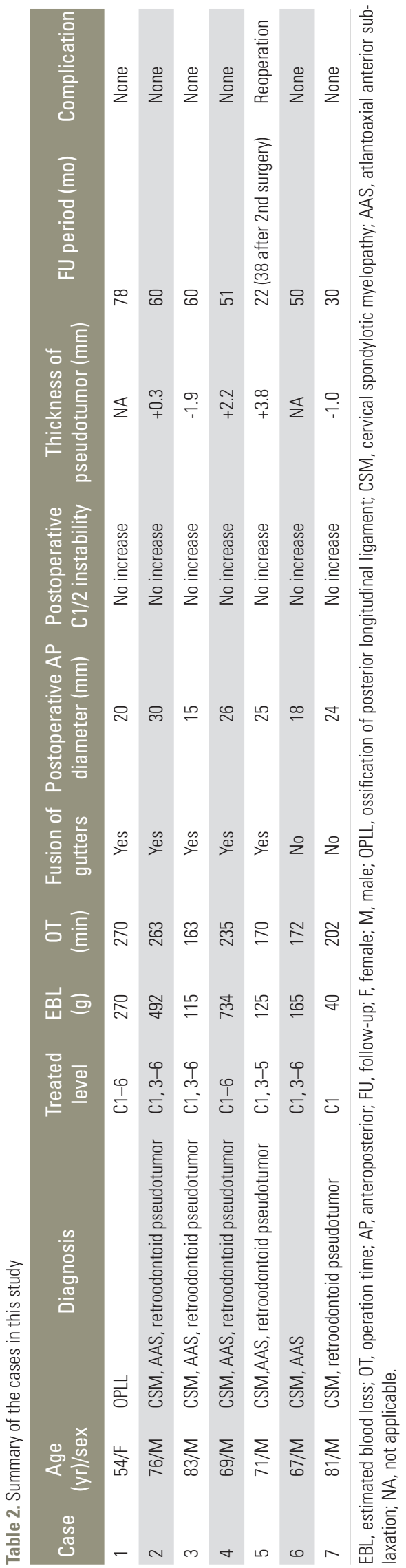


Table 3. The JOA score and recovery rate of the patients

\begin{tabular}{|c|c|c|c|c|c|}
\hline \multirow{2}{*}{ Case } & \multicolumn{3}{|c|}{ JOA score } & \multicolumn{2}{|c|}{ Recovery rate (\%) } \\
\hline & Preoperation & At 1 year after surgery & Final FU & At 1 year after surgery & Final FU \\
\hline 1 & 6 & 12.5 & 13.5 & 59.1 & 68.2 \\
\hline 2 & 6.5 & 11.5 & 8.5 & 47.6 & 19.0 \\
\hline 3 & 10 & 14 & 14.5 & 57.1 & 64.3 \\
\hline 4 & 12.5 & 15.5 & 16 & 66.7 & 77.8 \\
\hline 5 & 12 & 14 & 12 & 40.0 & 0 \\
\hline 6 & 10.5 & 13.5 & 13 & 46.2 & 38.5 \\
\hline 7 & 2.5 & 4.5 & 4.5 & 13.8 & 13.8 \\
\hline Mean & 8.6 & 12.2 & 11.7 & 42.9 & 40.2 \\
\hline
\end{tabular}

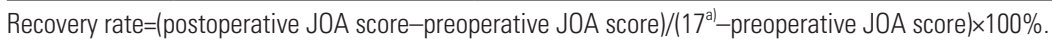

JOA, Japanese Orthopaedic Association; FU, follow-up.

a) 17 is the maximum JOA score.

the bone loop of $\mathrm{C} 1$ was maintained through contact with the HA spacer in all cases; however, apparent bone union between the HA spacer and posterior elements could not be confirmed. There were no major peri- or postoperative complications that seemed to be unique to C1 laminoplasty during the $\mathrm{FU}$.

One patient required additional fusion surgery (Magerl and Brooks procedure) due to neurological deterioration caused by an increase in the size of the pseudotumor at 22 months after $\mathrm{C} 1$ laminoplasty. The secureness of an adequate bone-grafting site around $\mathrm{C} 1$ was confirmed during salvage surgery. Four years have passed since salvage fusion surgery, and the patient has acquired solid bone union and is living well.

\section{Discussion}

We investigated the radiographic and clinical results of $\mathrm{C} 1$ laminoplasty for the patients with compressive myelopathy at the $\mathrm{C} 1$ level. Though one case required revision surgery, our results indicated that $\mathrm{C} 1$ laminoplasty might be a useful alternative procedure to $\mathrm{C} 1$ laminectomy based on the middle-term FU.

Generally, treatment for $\mathrm{C} 1$ compressive myelopathy is considered as fusion with instrumentation surgery, decompression surgery without fusion, or decompression and fusion with instrumentation surgery, depending on the condition of the patients. Most patients with instability at the C1/2 level are usually treated by fusion surgery with or without decompression. However, fusion surgery for patients without instability at the C1/2 level is contro- versial $[2,13,14]$.

Previous reports have recommended fusion surgery as the first choice for retroodontoid pseudotumor causing myelopathy [14-17]. However, C1 laminectomy without fusion has been reported to be a good procedure for patients without instability at the C1/2 level $[1,2]$. In addition, C1 laminoplasty has also been reported as a good procedure for patients with cervical myelopathy associated with retroodontoid pseudotumor without obvious C1-2 instability [13]. Decompression procedures, including laminectomy and laminoplasty, have some benefits over fusion surgery, such as a maintained range of motion, a reduced risk of vertebral artery injury, and absence of pain at the site of bone graft harvest. C1 laminoplasty is performed instead of $\mathrm{C} 1$ laminectomy whenever possible in our institution for patients with compressive myelopathy at the $\mathrm{C} 1$ level without obvious instability.

In this study, five patients had retroodontoid pseudotumor. One of them needed additional fusion surgery during FU due to neurological deterioration caused by an increase in the size of the retroodontoid pseudotumor. This patient showed pre-existing bone union of $\mathrm{C} 2 / 3$ at the first surgery. The size of the retroodontoid pseudotumor might have increased due to the mechanical load applied to the adjacent level. However, no apparent increase in the size of the retroodontoid pseudotumor was observed in the other four patients. The clinical results of these patients improved and maintained based on the JOA scores. C1 laminoplasty may therefore be suitable as a decompression procedure. However, a previous report described retroodontoid pseudotumor with myelopathy 
in a diffuse idiopathic skeletal hyperostosis patient with decreased cervical mobility [18]. Even if there is no obvious instability at the $\mathrm{C} 1 / 2$ level, close attention should be paid in patients with pre-existing subaxial ankylosis.

C1 laminoplasty might provide adequate decompression as that of laminectomy. Previous reports have found that the normal AP diameter at the level of the atlas ranges from 16 to $20 \mathrm{~mm}$ [19]. In this study, the mean canal AP diameter after $\mathrm{C} 1$ laminoplasty was $23 \mathrm{~mm}$, suggesting this procedure achieves adequate decompression at the level of the atlas.

C1 laminoplasty might have some benefits over laminectomy. Recently, a few cases of spontaneous $\mathrm{C} 1$ anterior arch fracture due to $\mathrm{C} 1$ laminectomy without obvious trauma were reported [1-6]. Most of these patients complained of neck pain. Four of them underwent fusion surgery, two required $\mathrm{C} 1 / 2$ or $\mathrm{C} 1-3$ fusion, another two required $\mathrm{O}-\mathrm{C}$ fusion, and one underwent the infusion of bone morphogenetic protein- 2 at the fracture site followed by the placement of a halo vest for 3 months. While most cases were treated conservatively using a neck collar, if surgery was required after $\mathrm{C} 1$ laminectomy, then all such patients required fusion surgery. Unfortunately, one case in the current series underwent reoperation with fusion surgery using the Magerl technique. An adequate bonegrafting site at the $\mathrm{C} 1$ posterior arch was observed intraoperatively, and the patient has acquired solid bone union after revision surgery. $\mathrm{C} 1$ laminoplasty might therefore be superior to laminectomy due to the fact that it provides an adequate bone-grafting site. This merit might lead to successful salvage fusion surgery. Even in cases of primary fusion surgery, various methods for obtaining an adequate bone-grafting site have been reported, such as $\mathrm{C} 1$ domelike laminotomy, posterior $\mathrm{C} 1-2$ polyaxial screw-rod fixation [20], and C1 laminoplasty with spacer and titanium miniplate screw fixation [21]. C1 laminoplasty is a simple and useful decompression procedure for securing an adequate bone-grafting site if subsequent additional salvage fusion surgery is necessary.

The incidence and risk factors of anterior arch fracture of the atlas following $\mathrm{C} 1$ laminectomy were recently reported [7]. In that study, the authors mentioned that the anterior arch fracture after $\mathrm{C} 1$ laminectomy was not uncommon (14.2\%) and a large inferior facet angle and the presence of subaxial ankylosis were risk factors. Based on the findings of the patients who underwent reoperation in our series and previously reported data [7], fusion surgery might be better than decompression surgery for patients with subaxial ankylosis and/or large inferior facet angle. Shimizu et al. [6] suggested that C1 laminoplasty may be a prophylactic surgical intervention for anterior arch fracture. In the case of elderly patients with low activity concomitant to small inferior facet angle, C1 laminoplasty might be an option. To obtain further information regarding the association between $\mathrm{C} 1$ laminoplasty and prophylaxis of spontaneous anterior arch fracture, a larger number of cases and a biomechanical study similar to that conducted by Shimizu et al. [6] are needed.

Several limitations associated with this study warrant mention. First, this study examined a small number of cases. Thus, it is necessary to accumulate cases in the future. Second, this study was only an observational study. Hence, a comparative study with C1 laminectomy should be done.

C1 laminoplasty can obtain an adequate bone-grafting site around the $\mathrm{C} 1$ posterior part with HA spacer and suture without any screw or miniplate. This fact was confirmed in the case of reoperation in this series. In addition, no case of dynamic paraspinal muscle impingement causing neurological deterioration like that in the past literature was found in this series [9]. Consequently, C1 laminoplasty is a simple and better decompression procedure with possibilities and usefulness to replace $\mathrm{C} 1$ laminectomy in that it can prevent compression from the posterior tissue and obtain an adequate bone-grafting site around the $\mathrm{C} 1$ posterior part.

\section{Conclusions}

There were no complications that seemed to be unique to C1 laminoplasty in this series. C1 laminoplasty for patients without obvious segmental instability might be a viable alternative procedure to $\mathrm{C} 1$ laminectomy.

\section{Conflict of Interest}

No potential conflict of interest relevant to this article was reported.

\section{ORCID}

Kiyoshi Tarukado: https://orcid.org/0000-0001-6033-5492

Ko Ikuta: https://orcid.org/0000-0002-5351-2638

Keiichiro Iida: https://orcid.org/0000-0003-1720-407X 
Osamu Tono: https://orcid.org/0000-0002-9685-2122

Toshio Doi: https://orcid.org/0000-0002-4415-2474

Katsumi Harimaya: https://orcid.org/0000-0003-1118-4338

\section{References}

1. Takemoto M, Neo M, Fujibayashi S, et al. Clinical and radiographic outcomes of $\mathrm{C} 1$ laminectomy without fusion in patients with cervical myelopathy that is associated with a retro-odontoid pseudotumor. Clin Spine Surg 2016;29:E514-21.

2. Kakutani K, Doita M, Yoshikawa M, et al. C1 laminectomy for retro-odontoid pseudotumor without atlantoaxial subluxation: review of seven consecutive cases. Eur Spine J 2013;22:1119-26.

3. O'Shaughnessy BA, Salehi SA, Ali S, Liu JC. Anterior atlas fracture following suboccipital decompression for Chiari I malformation: report of two cases. J Neurosurg Spine 2004;1:137-40.

4. Hirano Y, Sugawara A, Mizuno J, Takeda M, Watanabe $\mathrm{K}$, Ogasawara $\mathrm{K}$. Spontaneous $\mathrm{C} 1$ anterior arch fracture as a postoperative complication of foramen magnum decompression for Chiari malformation type 1. Surg Neurol Int 2011;2:138.

5. Baghdassarian A, Piatt JH Jr, Giordano K. Fracture of the anterior arch of atlas after minor trauma of the immature spine postlaminectomy. Pediatr Emerg Care 2014;30:340-2.

6. Shimizu T, Otsuki B, Fujibayashi S, et al. Spontaneous anterior arch fracture of the atlas following $\mathrm{C} 1$ laminectomy without fusion: a report of three cases and finite element analysis. J Orthop Sci 2016;21:306-15.

7. Shimizu T, Otsuki B, Fujibayashi S, et al. Incidence and risk factors of anterior arch fracture of the atlas following C1 laminectomy without fusion. Spine (Phila Pa 1976) 2018;43:667-74.

8. Allam E, Zhou Y. Bipartite atlas or Jefferson fracture?: a case series and literature review. Spine (Phila Pa 1976) 2015;40:E661-4.

9. Notani N, Miyazaki M, Yoshiiwa T, Ishihara T, Kanezaki S, Tsumura H. Dynamic paraspinal muscle impingement causing acute hemiplegia after $\mathrm{C} 1$ posterior arch laminectomy: a case report. Medicine (Baltimore) 2017;96:e9264.

10. Japanese Orthopaedic Association. Scoring system for cervical myelopathy. J Jpn Orthop Assoc 1994;68:490-530.
11. Hirabayashi K, Miyakawa J, Satomi K, Maruyama T, Wakano K. Operative results and postoperative progression of ossification among patients with ossification of cervical posterior longitudinal ligament. Spine (Phila Pa 1976) 1981;6:354-64.

12. Fukui M, Chiba K, Kawakami M, et al. An outcome measure for patients with cervical myelopathy: Japanese Orthopaedic Association Cervical Myelopathy Evaluation Questionnaire (JOACMEQ): part 1. J Orthop Sci 2007;12:227-40.

13. Suetsuna F, Narita H, Ono A, Ohishi H. Regression of retroodontoid pseudotumors following C-1 laminoplasty: report of three cases. J Neurosurg Spine 2006;5:455-60.

14. Chikuda H, Seichi A, Takeshita K, et al. Radiographic analysis of the cervical spine in patients with retroodontoid pseudotumors. Spine (Phila Pa 1976) 2009;34:E110-4.

15. Sono T, Onishi E, Matsushita M. Radiographic risk factors and surgical outcomes for retroodontoid pseudotumors. J Spinal Disord Tech 2014;27:E193-8.

16. Yamaguchi I, Shibuya S, Arima N, Oka S, Kanda Y, Yamamoto T. Remarkable reduction or disappearance of retroodontoid pseudotumors after occipitocervical fusion: report of three cases. J Neurosurg Spine 2006;5:156-60.

17. Jun BY. Complete reduction of retro-odontoid soft tissue mass in os odontoideum following the posterior C1-C2 tranarticular screw fixation. Spine (Phila Pa 1976) 1999;24:1961-4.

18. Jun BY, Yoon KJ, Crockard A. Retro-odontoid pseudotumor in diffuse idiopathic skeletal hyperostosis. Spine (Phila Pa 1976) 2002;27:E266-70.

19. Sawada H, Akiguchi I, Fukuyama H, Kameyama M, Koyama T. Marked canal stenosis at the level of the atlas. Neuroradiology 1989;31:346-8.

20. Yamazaki M, Okawa A, Mannoji C, Kadota R, Miyashita T, Koda M. C1 dome-like laminotomy and posterior C1-C2 polyaxial screw-rod fixation for a patient with cervical myelopathy due to a retroodontoid pseudotumor. J Clin Neurosci 2009;16:99103.

21. Kim SW, Lee JH, Lee HW, Oh JK, Kwak YH. New technique for $\mathrm{C} 1$ double-door laminoplasty using allograft spacers and titanium miniplate screw fixation: technical report. J Neurol Surg A Cent Eur Neurosurg 2016;77:155-60. 